\title{
Capacidade tamponante, pH e consistência das fezes em equinos submetidos à sobrecarga dietética com amido
}

\author{
Buffer capacity, pH and faeces consistency in horses submitted to dietetic starch overload
}

\author{
Tiago Marques dos Santos ${ }^{\mathrm{I}}$ Fernando Queiroz de Almeida ${ }^{\mathrm{II}}$ Fernanda Nascimento de Godoi ${ }^{\mathrm{II}}$ \\ Vinícius Pimentel Silva ${ }^{\text {III }}$ Almira Biazon França ${ }^{\text {III }}$ Juliano Martins Santiago $^{\text {IV }}$ \\ Caroline Spitz dos Santos ${ }^{\mathrm{IV}}$
}

\section{RESUMO}

Este trabalho teve como objetivo avaliar a capacidade tamponante (CT), o pH e a consistência das fezes em equinos submetidos à sobrecarga dietética com amido. Seis equinos adultos foram submetidos à sobrecarga com infusão gástrica de 17,6g de amido $\mathrm{kg}^{-1}$ de peso corporal através de sonda nasogástrica. Amostras fecais foram coletadas, antes e quatro, oito, 12, 16, 20, 24, 28, 32 e 36 horas pós-sobrecarga, e imediatamente submetidas à avaliação do $\mathrm{pH}$, da CT e da consistência. Os resultados de $\mathrm{pH}$ foram comparados pelo teste t de student $(P<0,05)$. Já os resultados da CT e consistência fecal foram comparados pelo teste de Kruskal-Wallis $(P<0,05)$ e submetidos à análise de regressão e correlação de Spearman em função do tempo após a sobrecarga. Houve redução $(\mathrm{P}>0,05)$ no $\mathrm{pH}$ fecal ao longo de 36 horas pós-sobrecarga, com valores médios variando de 6,09 a 4,46. A partir do modelo $\mathrm{pH}=6,083-0,003 t-0,001 t^{2}\left(R^{2}=0,634\right)$, houve decréscimo de 0,004 no $\mathrm{pH}$ fecal a cada hora, de 0,028 a cada quatro horas e de 1,404 ao final de 36 horas após a sobrecarga, respectivamente. Além do $\mathrm{pH}$, houve redução $(P<0,05)$ na $C T$ das fezes, em função do tempo após a sobrecarga. Observouse correlação positiva $(r=0,65 ; \mathrm{P}<0,0001)$ entre o $\mathrm{pH}$ e a $C T$ das fezes. Todos os equinos apresentaram fezes de consistência normal (escore 3) até a oitava hora após a sobrecarga. Posteriormente, esses animais apresentaram redução na consistência fecal $(P<0,05)$ até 36 horas. Os resultados demonstram que a sobrecarga dietética com amido promove redução na consistência fecal, na capacidade tampão e consequentemente no $\mathrm{pH}$ das fezes em equinos.

Palavras-chave: carboidratos, cavalos, dietas, $\mathrm{pH}$ fecal.

\begin{abstract}
This study aimed to evaluate buffer capacity (BC), $\mathrm{pH}$ and faeces consistency of horses submitted to dietetic starch overload. Six crossbreed mature horses were submitted to starch overload with gastric infusion of $17.6 \mathrm{~g}$ starch $\mathrm{kg}^{-1}$ body weight through nasogastric tube. Faecal samples were collected, before and at 4, 8, 12, 16, 20, 24, 28, 32 and 36 hours post-overload, and immediately submitted to evaluation of $\mathrm{pH}, \mathrm{BC}$ and consistency. The $\mathrm{pH}$ data were compared by $t$ student test $(P<0.05)$. The $B C$ and fecal consistency were compared by Kruskal-Wallis test $(P<0.05)$ and submitted to regression analysis and Spearman correlation in function of the time after overload. There was faecal $\mathrm{pH}$ decreased along 36 hours postoverload $(P>0.05)$, with means values varying from 6.09 to 4.46. Based on the model $p H=6.083-0.003 t-0.001 t^{2}\left(R^{2}=\right.$ $0.634)$, faecal $p H$ decreased 0.004 per hour, 0.028 to each four hours and 1.404 at 36 hours after overload, respectively. As $p H$, faeces $B C$ decreased $(P<0.05)$ in function of the time after overload. Positive relationship was observed $(r=0.65$; $P<0.0001$ ) between $p H$ and $B C$ of faeces. All horses presented normal consistency faeces (score 3) until eight hours after overload, following by reduction $(P<0.05)$ up to 36 hours. Results demonstrated that starch overload reduce faecal consistency, buffer capacity and $\mathrm{pH}$ in horses faeces.
\end{abstract}

Key words: carbohydrate, horses, diets, faecal $\mathrm{pH}$.

\section{INTRODUÇÃO}

Distúrbios gastrointestinais correspondem aos principais problemas clínicos em equinos e, dentre

ICurso de Pós-graduação em Ciências Veterinárias, Instituto de Veterinária, Universidade Federal Rural do Rio de Janeiro (UFRRJ), Seropédica, RJ, Brasil.

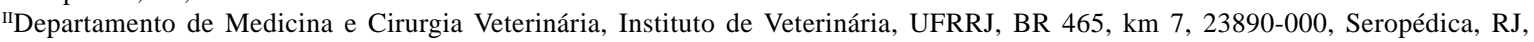
Brasil. E-mail: falmeida@ufrrj.br. Autor para correspondência.

IIIPrograma de Pós-graduação em Zootecnia, UFRRJ, Seropédica, RJ, Brasil.

${ }^{\mathrm{IV}}$ Curso de Medicina Veterinária, UFRRJ, Seropédica, RJ, Brasil. 
eles, a cólica é responsável por causar maior número de mortes (TRAUB-DARGATZ et al., 1991; 2001). Alguns estudos epidemiológicos e experimentais citam as práticas de alimentação e dietas contendo grandes quantidades de carboidratos hidrolisáveis e pequenas quantidades de fibras como os principais fatores de risco para ocorrência de cólica em equinos (CLARKE et al., 1990; REEVES et al., 1996; TINKER et al., 1997; HUDSON et al., 2001) e acidemia intestinal pós-prandial (ROWE et al., 1994).

Estudos demonstram que equinos consumindo dietas ricas em carboidratos hidrolisáveis (HUSSEIN et al., 2004; RICHARDS et al., 2006; WILLIAMSON et al., 2007; BERG et al., 2008) e submetidos à sobrecarga dietética com amido (POLLIT \& DAVIES, 1998) apresentam redução no $\mathrm{pH}$ fecal. Isso se deve ao consumo excessivo de carboidratos na dieta, o qual resulta na fermentação do amido no intestino grosso, levando ao aumento na produção de ácidos graxos voláteis (AGVs) e ácido láctico (ZEYNER et al., 2004).

A metodologia de sobrecarga dietética com amido em equinos é utilizada com o objetivo de estudar a patofisiologia da laminite (GARNER et al., 1975; GARNER et al., 1977; GARNER et al., 1978; SPROUSE et al., 1987; POLLITT \& DAVIES, 1998; PAES LEME et al., 2006; MARTINS FILHO et al., 2007). Nesse contexto, há escassez de conhecimento em relação às alterações nas fezes provocadas pela sobrecarga. O conhecimento das características físico-químicas das fezes poderá facilitar o diagnóstico de acidose intestinal, evitando quadros de cólica, endotoxemia e laminite. Amensuração do $\mathrm{pH}$ fecal foi proposta por RICHARDS et al. (2006) como método satisfatório e não invasivo para quantificação indireta de acidose no intestino grosso de equinos. Dessa forma, este estudo tem como objetivo avaliar o $\mathrm{pH}$, a capacidade tamponante (CT) e a consistência das fezes de equinos submetidos à sobrecarga dietética com amido.

\section{MATERIAL E MÉTODOS}

Foram utilizados seis equinos mestiços adultos, com peso corporal variando de 335 a 393kg, castrados e com idade entre 17 e 27 anos. No período pré-experimental, os equinos foram submetidos à vermifugação (Equalan ${ }^{\circledR}$ ) e ao controle de ectoparasitos $\left(\right.$ Butox $\left.^{\circledR}\right)$ e mantidos à pasto. Durante o período experimental, os equinos formam mantidos exclusivamente em baias de alvenaria de $3 \mathrm{~m}$ x 3m, com cochos separados para ração e água. Os animais foram alimentados durante 15 dias com dieta experimental composta por feno de capim Coastcross e ração concentrada (Corcelina, Purina ${ }^{\circledR}$ ), na proporção de
$60: 40$, equivalente a $2,5 \%$ do peso corporal, baseado na matéria seca, segundo recomendações do National Research Council - NRC (1989). A dieta foi dividida em quatro refeições diárias, intercalando a ração concentrada e o volumoso, às 6, 11, 16 e 21 horas.

O delineamento experimental foi inteiramente casualizado em função do tempo que correspondeu aos tratamentos, sendo o animal a unidade experimental. Os seis equinos foram submetidos à sobrecarga dietética com amido e às coletas de amostras de fezes antes da indução e às 4, 8, 12, 16, 20, 24, 28, 32 e 36 horas após a sobrecarga. A sobrecarga foi realizada com os animais em jejum hídrico de 12 horas, utilizando amido de milho (Maizena - Duryea ${ }^{\circledR}$ ), via sonda nasogástrica, na proporção de 17,6g amido $\mathrm{kg}^{-1}$ de peso corporal (GARNER et al., 1975), diluído em água na proporção de $757 \mathrm{~g}$ de amido em $1.000 \mathrm{~mL}$ de água. A indução ocorreu durante uma hora, em três etapas, com a administração de 1/3 do amido de milho diluído em água por etapa. A sonda nasogástrica foi previamente lubrificada, e a infusão gástrica do amido foi realizada por gravidade, de forma lenta, para evitar estresse ao animal.

As amostras de fezes foram coletadas da ampola retal de cada animal utilizando sacos plásticos e, em seguida, foi realizada avaliação imediata do $\mathrm{pH}$ através de pHmetro (Tecnopon, PA 2000). A CT foi avaliada segundo metodologia descrita por ZEYNER et al. (2004). Uma alíquota de 50g de cada amostra fecal foi adicionada à água destilada na relação $1: 1$ peso/ volume, e a CT foi estimada por titulação com ácido acético 0,25M em $80 \mathrm{~mL}$ de fezes misturadas à água. A $\mathrm{CT}_{1}$ refere-se ao volume gasto de ácido acético necessário para promover a alteração do $\mathrm{pH}$ observado na amostra para o $\mathrm{pH}=5$, e a $\mathrm{CT}_{2}$ refere-se ao volume gasto de ácido acético necessário para promover a alteração do $\mathrm{pH}$ observado para o $\mathrm{pH}=6$. O volume de ácido acético utilizado foi expresso em $\mathrm{mmol} \mathrm{L}^{-1}$ de fezes diluídas em água. A consistência fecal foi avaliada subjetivamente em escore com escala de 1 a 5 , sendo fezes extremamente ressecadas (1), fezes normais (3) e fezes diarréicas (5) (BERG et al., 2008).

Os valores referentes ao $\mathrm{pH}$ fecal foram submetidos à ANOVA e, quando significativos, comparados pelo teste $t$ de Student, a $5 \%$ de significância. Os dados de CT e consistência fecal foram submetidos ao teste não paramétrico de Kruskal-Wallis, a 5\% de significância. Os valores de pH e CT das fezes em função do tempo após a sobrecarga foram submetidos à análise de regressão e correlação de Spearman. As análises foram realizadas utilizando o programa Sistema de Análises Estatísticas e Genéticas - SAEG 8.0 (UFV, 2000) e, para elaboração das figuras, foi utilizado o programa SigmaPlot 8.0. 


\section{RESULTADOS E DISCUSSÃO}

A consistência das fezes dos equinos submetidos à sobrecarga dietética com amido pode ser observada na figura 1 . Todos os equinos apresentaram fezes de consistência normal (escore 3) até oito horas após a sobrecarga. Posteriormente, houve redução (escore 3,5) até 20 horas, porém sem diferença $(\mathrm{P}>0,05)$ dos momentos iniciais. A partir da $20^{\mathrm{a}}$ hora, houve redução $(\mathrm{P}<0,05)$ na consistência fecal até a $36^{\mathrm{a}}$ hora após a sobrecarga (escore 4,7). A redução na consistência fecal foi evidenciada pela fluidificação das fezes (escore 4), que evoluiu para quadros diarréicos (escore 5) após a $36^{a}$ hora da sobrecarga. Além disso, 24 horas após a sobrecarga, os animais apresentaram fezes com odor ácido, corroborando as alterações observadas em equinos submetidos à sobrecarga dietética com amido (HARKEMA et al., 1978; POLLITT \& DAVIES, 1998) ou consumindo dieta rica em carboidratos hidrolisáveis (ROWE et al., 1994). O processo de fluidificação das fezes é justificado pelo aumento da produção de ácido láctico no intestino grosso, o qual promove aumento da pressão osmótica intraluminal, resultando no fluxo de água para o lúmen intestinal (ROWE et al., 1994; ARGENZIO, 1996).

Os valores médios e desvio padrão do $\mathrm{pH}$, da $\mathrm{CT}_{1}$ ( $\mathrm{pH}$ observado - 5,0) e da $\mathrm{CT}_{2}(\mathrm{pH}$ observado $6,0)$ das fezes ao longo de 36 horas após a sobrecarga dietética com amido estão apresentados na tabela 1 . Antes e 32 horas após a sobrecarga, o pH fecal variou de 6,09 a 4,46, respectivamente, apresentando, em seguida, aumento $(\mathrm{P}>0,05) 36$ horas após a sobrecarga. Houve redução no pH fecal até 16 horas após a sobrecarga, porém não diferiu $(\mathrm{P}>0,05)$ do $\mathrm{pH}$ antes da sobrecarga, de 5,92 e 6,04, respectivamente. A partir de 16 horas da sobrecarga houve redução $(\mathrm{P}<0,05)$ acentuada no $\mathrm{pH}$ fecal até 36 horas.

A redução do $\mathrm{pH}$ fecal observada no presente estudo corrobora os resultados observados por POLLITT \& DAVIES (1998) antes e 24 horas após a sobrecarga, de 7,4 e 5,23, respectivamente. Nesse estudo, o $\mathrm{pH}$ fecal antes da sobrecarga foi de 7,4, superior ao do presente estudo, de 6,09, o que se justifica pelo fato de a dieta dos equinos do presente estudo ser composta de feno:concentrado na proporção 60:40. No estudo de POLLITT \& DAVIES (1998), por sua vez, a dieta foi exclusiva de feno.

A CT das fezes na espécie equina é muito pouco estudada, porém é um parâmetro importante na avaliação de distúrbios digestivos envolvendo dietas ricas em carboidratos hidrolisáveis, normalmente utilizadas para equinos. Segundo ZEYNER et al. (2004), a CT entre o $\mathrm{pH}$ observado e qualquer valor de $\mathrm{pH}$ definido representa o potencial real do meio em reagir contra modificações influenciadas pela produção de ácidos. Com base nesse conceito, houve redução

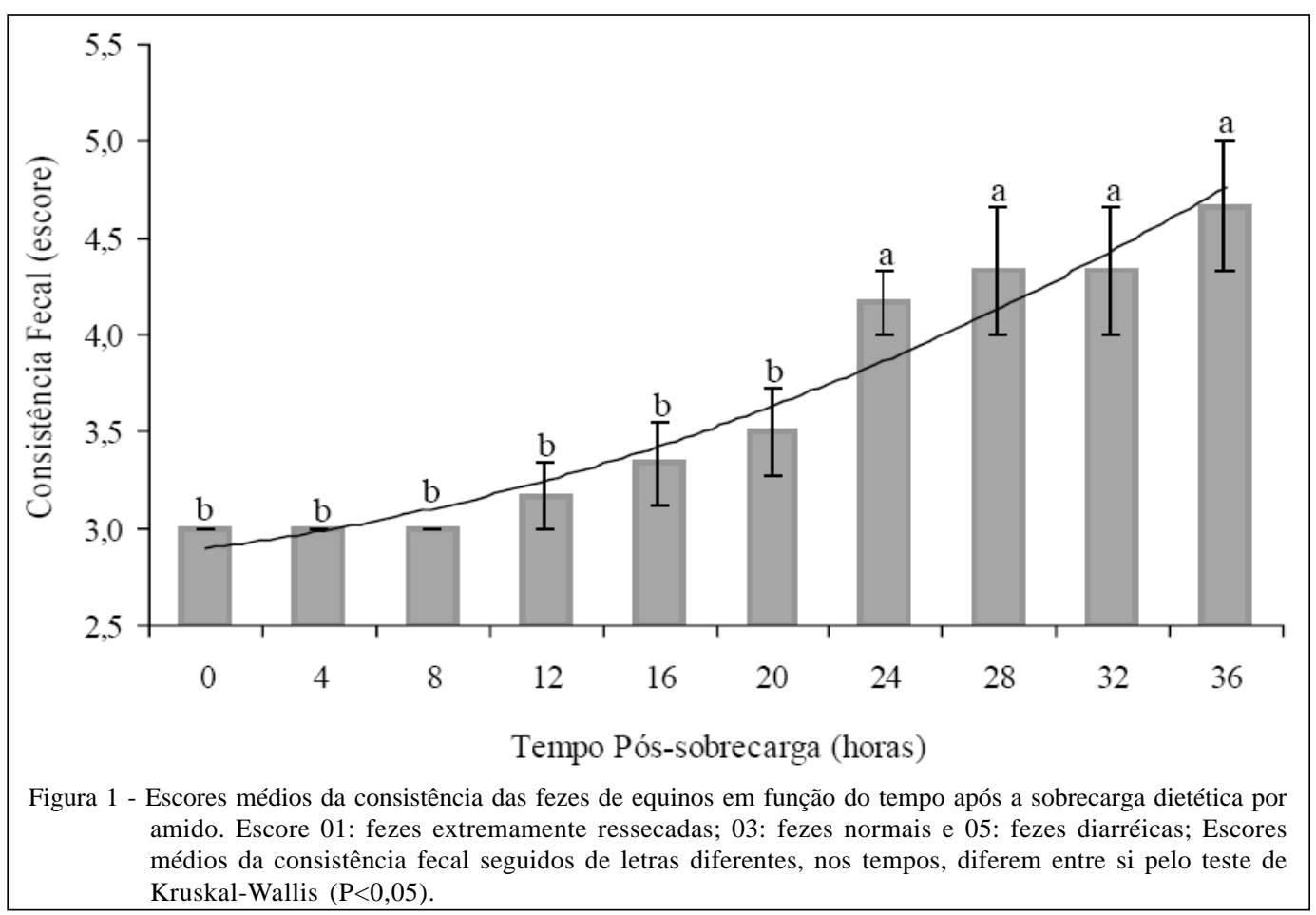

Ciência Rural, v.39, n.6, set, 2009. 
Tabela 1 - Valores médios e desvio padrão do $\mathrm{pH}$ e da capacidade tampão $\left(\mathrm{CT}_{1}\right.$ e $\left.\mathrm{CT}_{2}\right)$ das fezes de equinos submetidos à sobrecarga dietética com amido.

\begin{tabular}{llccc}
\hline Tempo Pós-sobrecarga (Horas) & $\mathrm{n}$ & $\mathrm{pH} \mathrm{Fecal}^{\mathrm{I}}$ & $\mathrm{CT}_{1}{ }^{\mathrm{II}}\left(\mathrm{mmol} \mathrm{L}^{-1}\right)$ & $\mathrm{CT}_{2}{ }^{\mathrm{II}}\left(\mathrm{mmol} \mathrm{L}^{-1}\right)$ \\
\hline 0 & 6 & $6,1 \pm 0,3^{\mathrm{a}}$ & $16,5 \pm 5,0^{\mathrm{a}}$ & $3,1 \pm 1,7^{\mathrm{a}}$ \\
4 & 6 & $6,0 \pm 0,3^{\mathrm{a}}$ & $15,6 \pm 6,9^{\mathrm{a}}$ & $3,2 \pm 2,3^{\mathrm{a}}$ \\
8 & 6 & $5,9 \pm 0,2^{\mathrm{a}}$ & $13,6 \pm 5,0^{\mathrm{a}}$ & $0,8 \pm 0,4^{\mathrm{b}}$ \\
12 & 6 & $5,9 \pm 0,3^{\mathrm{a}}$ & $11,8 \pm 4,0^{\mathrm{a}}$ & $0,8 \pm 0,2^{\mathrm{b}}$ \\
16 & 6 & $5,9 \pm 0,3^{\mathrm{a}}$ & $11,2 \pm 2,1^{\mathrm{a}}$ & $1,0 \pm 0,3^{\mathrm{b}}$ \\
20 & 6 & $5,6 \pm 0,2^{\mathrm{b}}$ & $7,9 \pm 1,8^{\mathrm{ab}}$ & $* *$ \\
24 & 6 & $5,2 \pm 0,6^{\mathrm{c}}$ & $8,5 \pm 3,2^{\mathrm{b}}$ & $* *$ \\
28 & 3 & $5,0 \pm 0,5^{\mathrm{d}}$ & $*$ & $* *$ \\
32 & 2 & $4,5 \pm 0,5^{\mathrm{e}}$ & $*$ & $* *$ \\
36 & 2 & $4,8 \pm 0,7^{\mathrm{d}}$ & $*$ & \\
$\mathrm{CV}(\%)$ & & & & $* *$ \\
\hline
\end{tabular}

${ }^{\mathrm{I}}$ Médias, na coluna, seguidas de letras diferentes diferem entre si pelo teste t de Student $(\mathrm{P}<0,05)$.

${ }^{\text {II }}$ Médias, nas colunas, seguidas de letras diferentes diferem entre si pelo teste de Kruskal-Wallis $(\mathrm{P}<0,05)$.

* $\mathrm{pH}$ fecal abaixo de 5,0; ** $\mathrm{pH}$ fecal abaixo de 6,0.

n: Número de animais em cada tempo; $\mathrm{CT}_{1}$ : volume de ácido acético gasto para promover a redução do $\mathrm{pH}$ observado na amostra para o pH

= 5; $\mathrm{CT}_{2}$ : volume de ácido acético gasto para promover a redução do $\mathrm{pH}$ observado na amostra para o pH = 6; $\mathrm{CV}$ : Coeficiente de variação.

$(\mathrm{P}<0,05)$ na $\mathrm{CT}_{2}(\mathrm{pH}$ observado - 6,0) antes e até 16 horas após a sobrecarga, com valores de 3,05e 1,02mmol $\mathrm{L}^{-1}$ (Tabela 1). A partir desse momento, os equinos não foram capazes de manter o $\mathrm{pH}$ fecal acima de 6,0, o que sugere estar apresentando quadro de acidose subclínica, uma vez que o pH cecal abaixo de 6,0 é característico desse quadro (RADICKE et al., 1991).

Em relação à $\mathrm{CT}_{1}(\mathrm{pH}$ observado - 5,0), também houve redução $(\mathrm{P}<0,05)$ na capacidade de tamponamento das fezes, com valores de 16,46 e 8,49 mmol L-1, antes e 24 horas após a sobrecarga, momento no qual os equinos não foram capazes de manter o pH fecal acima de 5,0. Em condições de sobrecarga por grãos, a capacidade de digestão do amido no intestino delgado é excedida e grandes quantidades de carboidratos hidrolisáveis são disponibilizadas para fermentação no intestino grosso.

Segundo POTTER et al. (1992), o limite máximo sugerido é de 3,5 a 4,0g de amido/kg de peso corporal por refeição. No entanto, KIENZLE (1994) sugerem que esse limite é inferior a 3,5g. O excesso de amido no intestino grosso seleciona rapidamente espécies de bactérias amilolíticas (JULLIAND et al., 2001; BAILEY et al., 2003), o que resulta na fermentação do amido e produção de grandes quantidades de ácido láctico (GARNER et al., 1978; GOODSON et al., 1988). O ácido láctico causa irritação no epitélio de revestimento intestinal, sobrepõe a capacidade de tamponamento normal do intestino e diminui o $\mathrm{pH}$ do seu conteúdo (PAGAN, 1998).
O efeito do tempo após a sobrecarga dietética com amido no $\mathrm{pH}$ fecal está representado na figura 2. A redução observada no $\mathrm{pH}$ fecal apresentou resposta quadrática $\mathrm{pH}=6,083-0,003 \mathrm{t}-0,001 \mathrm{t}^{2} ; \mathrm{R}^{2}=$ 0,634). Segundo o modelo proposto, a sobrecarga dietética com amido promoveu redução $(\mathrm{P}<0,05)$ de 0,004 no $\mathrm{pH}$ fecal a cada hora e de 0,028 e 1,404 a cada quatro e ao final de 36 horas após a sobrecarga, respectivamente. O efeito quadrático observado $(\mathrm{pH}$ fecal vs tempo pós-sobrecarga) se deve ao sucesso no tamponamento das fezes, nas primeiras horas após a sobrecarga, seguido de redução na CT e consequentemente no $\mathrm{pH}$ fecal.

$\mathrm{A} \mathrm{CT}_{1}$ das fezes em função do tempo após a sobrecarga dietética com amido está representada na figura 3. A redução observada na $\mathrm{CT}_{1}$ das fezes apresentou resposta linear $\left(\mathrm{CT}_{1}=16,62-0,37 \mathrm{t}\right.$; $\mathrm{R}^{2}=$ 0,35). Considerando o modelo proposto, a sobrecarga dietética com amido promoveu redução $(\mathrm{P}<0,05)$ de 0,37 $\mathrm{mmol} \mathrm{L}^{-1}$ na CT das fezes a cada hora e de 1,48 e $8,88 \mathrm{mmol} \mathrm{L}^{-1}$ a cada quatro e ao final de 24 horas após a sobrecarga, respectivamente. $\mathrm{O}$ baixo coeficiente de determinação $\left(\mathrm{R}^{2}=0,35\right)$ observado se deve à alta variação individual apresentada pelos equinos em relação à capacidade de tamponamento fecal sob condições de sobrecarga dietética com amido.

Quando relacionados o $\mathrm{pH}$ e a $\mathrm{CT}_{1}$, observou-se correlação positiva $(\mathrm{r}=0,65 ; \mathrm{P}<0,0001)$ (Figura 4). A redução na $\mathrm{CT}_{1}$ de $1,48 \mathrm{mmol} \mathrm{L}^{-1}$, a cada quatro horas, em função da sobrecarga, foi capaz de 


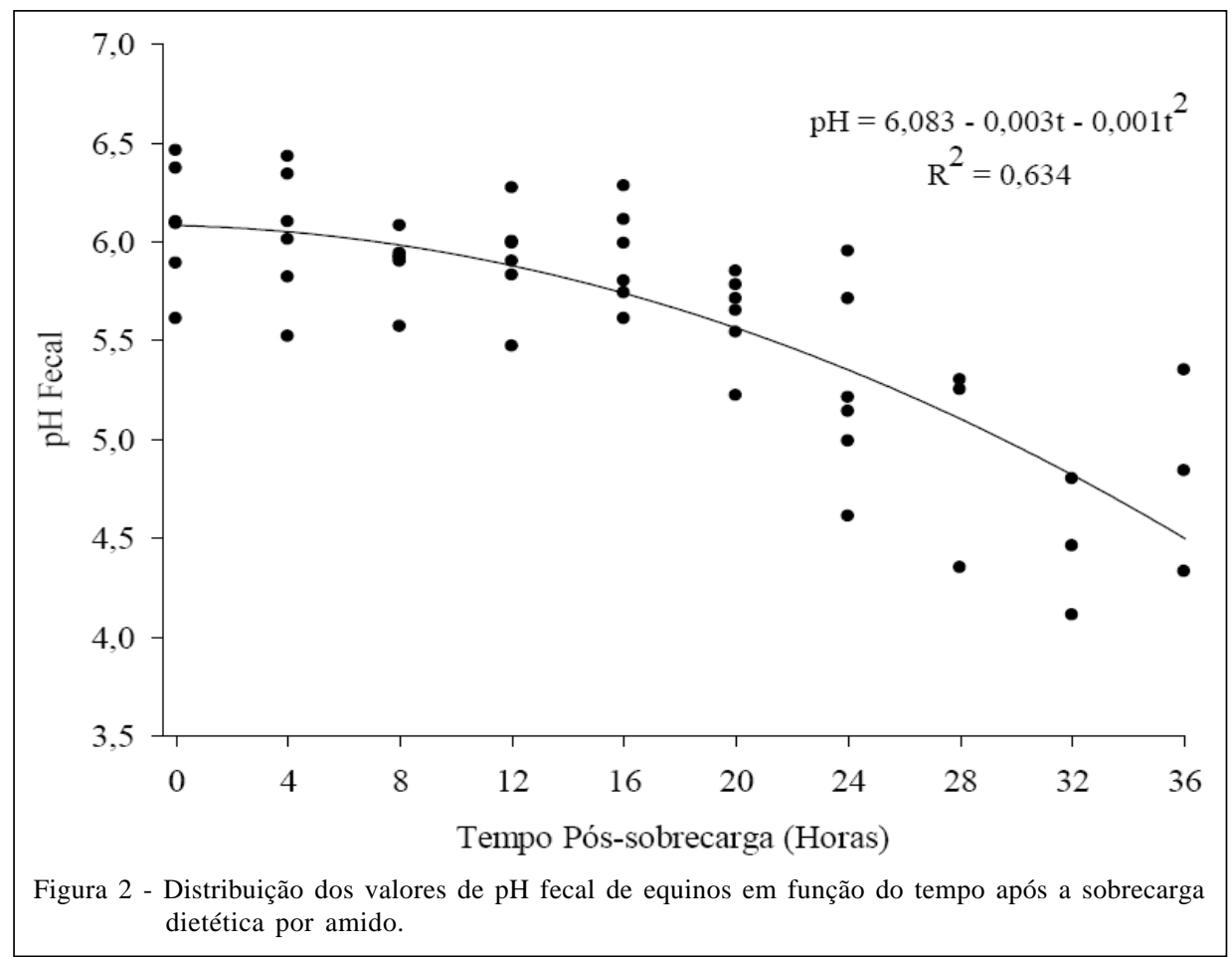

promover redução de 0,028 no $\mathrm{pH}$ fecal. Isso demonstra o efeito do processo fermentativo do amido na capacidade de tamponamento e manutenção do $\mathrm{pH}$ fecal, em equinos sob condições de sobrecarga dietética com amido ou provavelmente na utilização de dietas ricas em carboidratos hidrolisáveis (BERG et al., 2008; RICHARDS et al., 2006; WILLIAMSON et al., 2007).

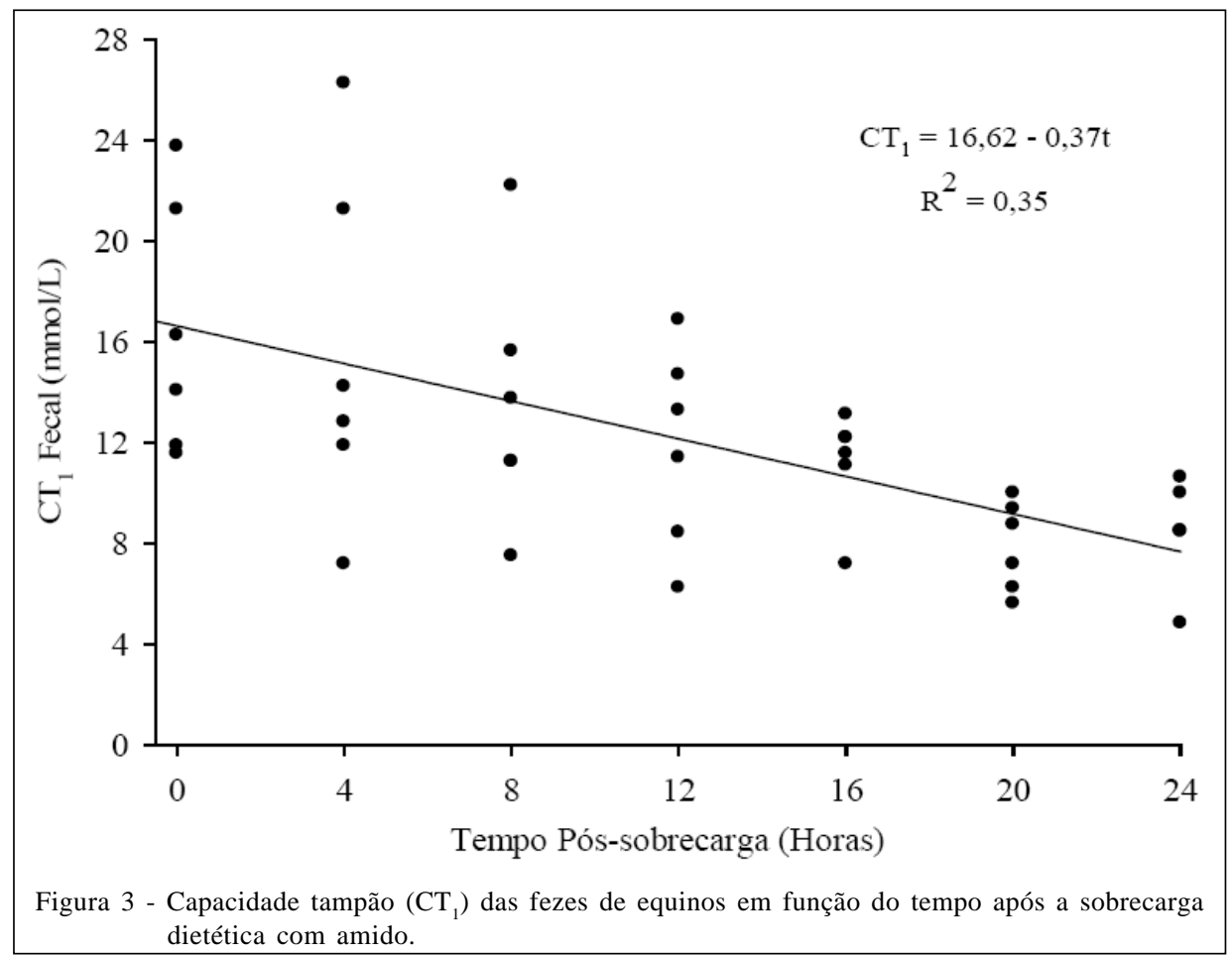

Ciência Rural, v.39, n.6, set, 2009. 


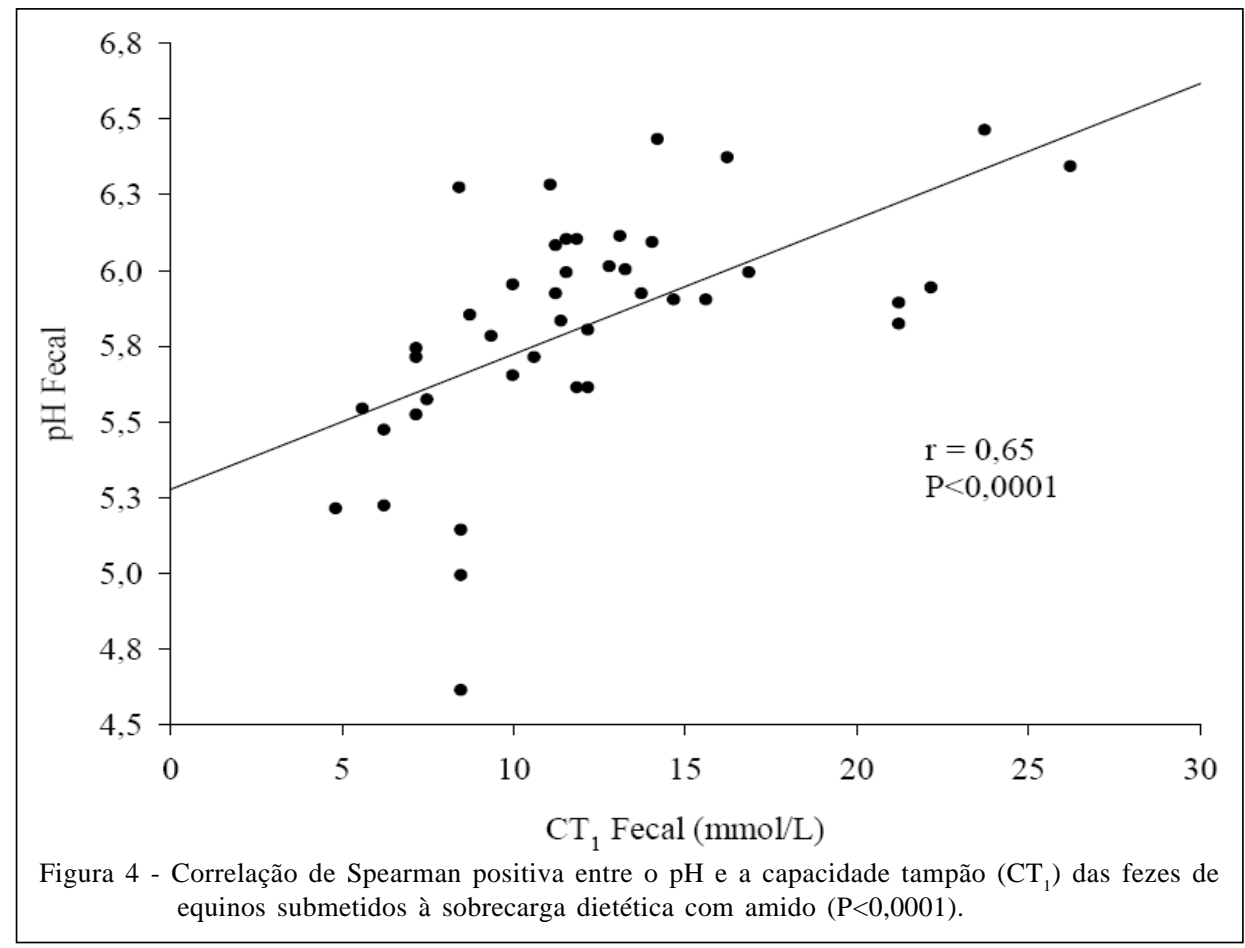

Os principais sistemas-tampão que operam no intestino grosso de equinos e que podem influenciar o $\mathrm{pH}$ fecal são os tampões bicarbonato $\left(\mathrm{HCO}_{3}^{-}\right)$e fosfato $\left(\mathrm{PO}_{4}^{3-}\right)$. O HCO ${ }_{3}^{-}$é secretado no duodeno pelo pâncreas, no íleo e em menor quantidade no intestino grosso (ARGENZIO, 1996). Além deste, o $\mathrm{PO}_{4}^{3-}$ resultante do metabolismo da dieta também pode contribuir para a neutralização do conteúdo intestinal em equinos. $\mathrm{O}$ $\mathrm{PO}_{4}^{3-}$ é fracamente absorvido pelo intestino. Portanto, à medida que a dieta é progressivamente absorvida, sua concentração aumenta nos conteúdos do lúmen (ARGENZIO, 1996). Segundo WILLIAMSON et al. (2007), o fornecimento de feno duas vezes ao dia e o aumento da quantidade de fibra na dieta estão associados com aumento no $\mathrm{pH}$ fecal. O feno ou as forragens ricas em fibra podem tamponar potencialmente os produtos da fermentação no intestino grosso devido a seu conteúdo rico em matéria seca (NRC, 1989).

\section{CONCLUSÃO}

A partir dos resultados observados no presente estudo, conclui-se que a sobrecarga dietética com amido promove redução na CT e, consequentemente, no $\mathrm{pH}$ e na consistência fecal em equinos. Além disso, esses parâmetros fecais podem ser utilizados como método indireto para estimar a acidose no intestino grosso dos equinos.

\section{COMISSÃO DE ÉTICA}

O experimento foi aprovado pela Comissão de Ética do Instituto de Veterinária da Universidade Federal Rural do Rio de Janeiro: 23083.011750/2006-33.

\section{REFERÊNCIAS}

ARGENZIO, R.A. Digestão e absorção dos carboidratos, gorduras e proteínas. In: DUKES, H.H. Fisiologia dos animais domésticos. 11.ed. Guanabara Koogan: Rio de Janeiro, 1996. Cap.19, p.330-342.

BAILEY, S.R. et al. Identification of equine cecal bacteria producing amines in an in vitro model of carbohydrate overload. Applied and Environmental Microbiology, v.69, n.4, p.2087-2093, 2003. Disponível em: <http:// w w w. p u b m e d c e n t r l. n i h. g o v/ picrender.fcgi ?artid $=154823 \&$ blobtype $=$ pdf $>$. Acesso em: 08 de maio de 2009. doi: 10.1128/AEM.69.4.2087-2093.2003.

BERG, E.L. et al. Fructooligosaccharide supplementation in the yearling horse: effects on fecal $\mathrm{pH}$, microbial content, and volatile fatty acid concentrations. Journal of Animal Science, v.83, n.7, p.1549-1553, 2008. Disponível em: <http:/ /jas.fass.org/cgi/content/full/83/7/1549>. Acesso em: 09 de maio de 2009 .

CLARKE, L.L. et al. Feeding and digestive problems in horses. Physiologic responses to a concentrated meal. Veterinary Clinics of North America: Equine Practice, v.6, n.2, p.433450, 1990.

GARNER, H.E. et al. Equine laminitis of alimentary origin: an experimental model. American Journal of Veterinary Research, v.36, n.4, p.441-444, 1975. 
GARNER, H.E. et al. Lactic acidosis: a factor associated with equine laminitis. Journal of Animal Science, v.45, n.5, p.1037-1041, 1977.

GARNER, H.E. et al. Changes in the caecal flora associated with the onset of laminitis. Equine Veterinary Journal, v.10, n.4, p.249-252, 1978.

GOODSON, J. et al. Effects of an abrupt change from hay to concentrate on microbial numbers and physical environment in the cecum of the pony. Applied and Environmental Microbiology, v.54, n.8, p.1946-1950, 1988.

HARKEMA, J.R. et al. Cardiovascular, acid-base, electrolyte, and plasma volume changes in ponies developing alimentary laminitis. American Journal of Veterinary Research, v.39, n.5, p.741-744, 1978.

HUDSON, J.M. et al. Feeding practices associated with colic in horses. Journal of the American Veterinary Medical Association, v.219, n.10, p.1419-1425, 2001.

HUSSEIN, H.S. et al. Effects of cereal grain supplementation on apparent digestibility of nutrients and concentrations of fermentation end-products in the feces and serum of horses consuming alfalfa cubes. Journal of Animal Science, v.82, n.7, p.1986-1996, 2004.

JULLIAND, V. et al. Feeding and microbial disorders in horses: 3-Effects of three hay:grain ratios on microbial profile and activities. Journal of Equine Veterinary Science, v.21, n.11, p.543-546, 2001. Disponível em: <http:// w w w. s c i e n c e d i r e c t . c o m / science?_ob=ArticleURL\&_udi=B 75GX-4HJYV 439\&_user $=687350>$. Acesso em: 09 de maio de 2009. doi:10.1016/S0737-0806(01)70159-1.

KIENZLE, E. Small intestinal digestion of starch in the horse. Revue du Médicine Véterinàrie, v.145, n.2, p.199-204, 1994.

MARTINS FILHO, L.P. et al. Estudo clínico e laboratorial da fase prodômica da laminite eqüina induzida por sobrecarga de carboidrato. ARS Veterinária, v.23, n.1, p.32-39, 2007.

NATIONAL RESEARCH COUNCIL - NRC. Nutrient requirements of horses. 5.ed. Washington, D. C., 1989. 100p.

PAES LEME, F.O. et al. Ativação de plaquetas de equinos com laminite induzida e tratados com ketropofeno, fenilbutazona e flunixin meglumina. Arquivo Brasileiro de Medicina Veterinária e Zootecnia, v.58, n.2, p.149-157, 2006.

PAGAN, J.D. Carbohydrates in equine nutrition. In: PAGAN, J.D. Advances in equine nutrition. Kentucky, USA: Kentucky Equine Research, 1998. p.57-70.

POLLITT, C.C.; DAVIES, C.T. Equine laminitis: its development coincides with increased sublamellar blood flow. Equine Veterinary Journal, v.28, n.26, p.125-132, 1998.

POTTER, G.D. et al. Digestion of starch in the small or large intestine of the equine. Pferdeheilkunde, v.1, n.4, p.107$111,1992$.
RADICKE, S. et al. Preileal apparent digestibility of oats and corn starch and consequences for cecal metabolism. In: EQUINE NUTRITION AND PHYSIOLOGY SOCIETY SYMPOSIUM, 12., 1992, Savoy, USA. Proceedings... Savoy: ENPS, 1991. p. $43-48$.

REEVES, M.J. et al. Risk factors for equine acute abdominal disease (colic): results from a multi-center case-control study. Preventive Veterinary Medicine, v.26, p.285301, 1996. Disponível em: <http://www.sciencedirect.com/ science?_ob=ArticleURL\&_udi=B6TBK-3VX9BN7B\&_user $=687350$ \&_rdoc $=1 \&$ fmt $=$ \&_orig $=$ search\&_sort $=\mathrm{d} \&$ view $=\mathrm{c} \& \_a c c t=$ C000037881\&_version $=1 \&$ \&urlVersion $=0$ \&_userid $=687$ $350 \& m d 5=4693 a 3289016 f 78711813 c d 6 e 0722$ efd $>$. Acesso em: 09 de maio de 2009. doi:10.1016/0167-5877(95)00551-X.

RICHARDS, N. et al. The effect of current grain feeding practices on hindgut starch fermentation and acidosis in the Australian racing Thoroughbred. Australian Veterinary Journal, v.84, n.11, p.402-407, 2006. Disponível em: <http:/ /www3.interscience.wiley.com/cgi-bin/fulltext/118568260/ PDFSTART>. Acesso em: 08 de maio de 2009. doi: 10.1111/ j.1751-0813.2006.0059.x.

ROWE, J.B. et al. Prevention of acidosis and laminitis associated with grain feeding in horses. Journal of Nutrition, v.124, n.12, p.2742S-2744S, 1994.

SPROUSE, R.F. et al. Plasma endotoxin levels in horses subjected to carbohydrate induced laminitis. Equine Veterinary Journal, v.9, n.1, p.25-28, 1987.

TINKER, M.K. et al. Prospective study of equine colic risk factors. Equine Veterinary Journal, v.29, n.6, p.454-458, 1997.

TRAUB-DARGATZ, J.L. et al. Estimate of the national incidence of and operation-level risk factors for colic among horses in the United States, spring 1998 to spring 1999. Journal of the American Veterinary Medical Association, v.219, n.1, p.67-71, 2001.

TRAUB-DARGATZ, J.L. et al. Medical problems of adult horses, as ranked by equine practitioners. Journal of the American Veterinary Medical Association, v.198, n.10, p.1745-1747, 1991.

UNIVERSIDADE FEDERAL DE VIÇOSA. SAEG - Sistema de análises estatísticas e genéticas. Viçosa: UFV, 2000. 150p. (Manual do usuário).

WILLIAMSON, A. et al. A survey of feeding, management and faecal $\mathrm{pH}$ of Thoroughbred racehorses in the North Island of New Zealand. New Zealand Veterinary Journal, v.55, n.6, p.337-341, 2007.

ZEYNER, A. et al. Effects of hay intake and feeding sequence on variables in faeces and faecal water (dry matter, $\mathrm{pH}$ value, organic acids, ammonia, buffering capacity) of horses. Journal of Animal Physiology and Animal Nutrition, v.88, n.1, p.719, 2004. Disponível em: <http://www3.interscience.wiley.com/ cgi-bin/fulltext/118789029/PDFSTART>. Acesso em: 09 de maio de 2009. doi: 10.1111/j.1439-0396.2004.00447.x.

Ciência Rural, v.39, n.6, set, 2009. 